\title{
A TESE 210 DA SUPREMA CORTE BRASILEIRA E A POSSÍVEL VIOLAÇÃO ÀS GARANTIAS CONSUMERISTAS: UMA ANÁLISE JURÍDICO ECONÔMICA DA PREVALÊNCIA DA CONVENÇÃO DE VARSÓVIA-MONTREAL.
}

\section{Matheus Barbosa Rodrigues*}

\section{RESUMO}

O artigo analisou a tese número 210 do Supremo Tribunal Federal, pelo qual a Suprema Corte decidiu que, no transporte internacional de passageiros, as indenizações por danos à bagagem são limitadas a 1000 Direitos Especiais de Saque, conforme o artigo 22, ponto 2 da Convenção de Varsóvia-Montreal. Utilizando-se dos métodos indutivo e dialético, observouse uma incompatibilidade entre a tese firmada e a garantia da reparação integral do dano, da proteção ao consumidor e o conceito de eficiência da Análise Econômica do Direito. Portanto, referido entendimento é inconstitucional.

Palavras-chave: Transporte internacional de passageiros; Limitação de indenizações; Tese da Suprema Corte; Violação dos direitos do consumidor; Entendimento ineficiente.

\section{SUPREME COURT'S THESIS NUMBER 210 AND THE POSSIBLE VIOLATION OF CONSUMER GUARANTEES: AN ECONOMICAL-JUDICIAL ANALYSIS OF WARSAW-MONTREAL CONVENTION PREVAIL.}

\begin{abstract}
The article analysed the thesis number 210 of the Supreme Federal Court, whereby the Supreme Court ruled that, in international passenger transportation, compensation for baggage damage is limited to 1000 Special Drawing Rights, according to article 22, point 2 of the Warsaw-Montreal Convention. Using the inductive and dialectical methods, an incompatibility between the established thesis and the guarantee of full damage repair, consumer protection and the concept of efficiency of the Economic Analysis of Law was observed. Thus, such understanding is unconstitutional.
\end{abstract}

Keywords: International passenger transport; Compensation limitation; Supreme Court thesis; Violation of consumer rights; Innefficient understanding.

\section{INTRODUÇÃO}

No Brasil atual, em função do estímulo ao constante consumo, observa-se a ampliação do domínio do crédito, a ampliação das estratégias de marketing e a massificação na oferta de produtos e serviços (BENJAMIN e GRINOVER; 2017, p. 04).

Diante desse cenário, a Constituição Federal de 1988 (CF/88) consignou, em seu artigo $5^{\circ}$, XXXII, a defesa do consumidor como direito fundamental e compromisso estatal. 
Mais ainda, determinou-se, no artigo 48 do Ato das Disposições Constitucionais Transitórias (ADCT), que cabia ao Congresso Nacional elaborar o Código de Defesa do Consumidor (CDC), publicado em 11 de setembro de 1990.

Entretanto, apesar do contexto legal de proteção ao consumidor, o Supremo Tribunal Federal (STF), através dos acórdãos no Recurso Extraordinário nº 636.331, do Rio de Janeiro $\left(\operatorname{RE~} n^{\circ}\right.$ 636.331/RJ) e no Agravo em Recurso Extraordinário no 766.618, de São Paulo (ARE $\left.\mathrm{n}^{\circ} 766.618 / \mathrm{SP}\right)$, fixou a tese $\mathrm{n}^{\circ} 210$, in verbis:

\footnotetext{
Nos termos do art. 178 da Constituição da República, as normas e os tratados internacionais limitadores da responsabilidade das transportadoras aéreas de passageiros, especialmente as Convenções de Varsóvia e Montreal, têm prevalência em relação ao Código de Defesa do Consumidor.
}

Por sua vez, a Convenção de Varsóvia-Montreal, acima referida, em seu artigo 22, ponto 2, limita o valor das indenizações por perda, avaria, destruição ou atraso na bagagem à quantia de 1000 Direitos Especiais de Saque ou, conforme cotação de 29/04/2020, R\$ $7.403,90$.

Cotejando-se a tese fixada pela Suprema Corte brasileira com o ordenamento jurídico nacional, parece haver uma fragilização da reparação integral do dano e da defesa do consumidor, insculpidas no artigo 5, V, X e XXXII da Constituição Federal de 1988.

Assim, utilizando-se do método indutivo e dialético, o presente artigo terá a seguinte pergunta de pesquisa: a decisão do Supremo Tribunal Federal no RE nº 636.331/RJ e no ARE $\mathrm{n}^{\mathrm{o}} 766.618 / \mathrm{SP}$ viola o artigo 5, V e X e XXXII da Constituição Federal de $1988 ?$

Para responder essa pergunta, será inicialmente delineado o conteúdo constitucional da proteção ao consumidor, analisando os incisos acima referidos.

Após, serão estudados conceitos de eficiência elaborados por diferentes teóricos do movimento conhecido como Análise Econômica do Direito, quais sejam, Vilfredo Pareto, Robert Cooter, Thomas Ulen, Nicholas Kaldor, John Richard Hicks, Nicholas Mankiw, Ronald Coase e Richard Posner. Seguidamente, e com apoio da fundamentação constitucional construída no capítulo 1 , será elaborado um conceito de eficiência próprio aplicável ao caso em estudo.

Por fim, será feito o confronto e a síntese dos argumentos colocados, identificando a possível incompatibilidade entre o entendimento da Suprema Corte e as garantias ao 
consumidor estabelecidas na Constituição Federal de 1988, desconstruindo a incidência do enunciado do artigo 178, caput, CF/88.

\section{A PROTEÇÃO CONSTITUCIONAL AO CONSUMIDOR: uma análise do artigo 5, V, X e XXXII da Constituição Federal de 1988.}

A Constituição Federal de 1988 é, para Bonavides (2013, p. 57-59), a mais republicana e democrática de todas, pois foi a que mais positivou direitos fundamentais, favorecendo a consolidação de um Estado Social.

Os direitos fundamentais, por sua vez, englobam, entre outros, os direitos individuais e coletivos, previstos no art. $5^{\circ}, \mathrm{CF} / 88$, e que podem, consoante Sarlet (2013, p. 185-186) ser entendidos a partir das dimensões objetiva e subjetiva. A primeira determina que às normas que prevêem direitos subjetivos é atribuída função autônoma. Ademais, entre as consequências da dimensão objetiva dos direitos fundamentais estão: a eficácia irradiante dos mesmos e o dever estatal de proteção e efetivação decorrente da positivação dos direitos fundamentais.

A dimensão subjetiva, por sua vez, está relacionada à posição jurídica conferida pela Constituição Federal ao cidadão de poder exigir do Estado uma prestação positiva em prol da concretização do direito assegurado.

Do acima exposto, já se pode aduzir que a positivação de um direito no rol das garantias fundamentais impõe ao Estado um compromisso de efetivação do mesmo, consistindo sua fragilização em violação a um direito subjetivo do cidadão.

No que se refere aos artigos objeto do presente estudo, tem-se que todos foram positivados enquanto direitos fundamentais. Logo, tornou-se obrigação do Estado atuar na efetivação desses direitos, quais sejam: o direito de resposta, proporcional ao agravo, além da indenização pelos danos; a inviolabilidade da intimidade, da vida privada, da honra e da imagem, assegurada reparação; e o compromisso estatal de promoção da defesa do consumidor (respectivamente, incisos V, X e XXXII do artigo $5^{\circ}$ da Constituição Federal de 1988). 
Feita uma análise teórica acerca da topologia constitucional dos incisos objeto de estudo, indicando o consequente dever estatal de efetivação, parte-se, de pronto, ao estudo do núcleo de cada um desses direitos.

Principia-se pela análise conjunta dos incisos $\mathrm{V}$ e $\mathrm{X}$ do artigo $5^{\circ}$ da Constituição Federal de 1988. Optou-se pelo seu estudo conjunto porquanto é da interpretação simultânea dos mesmos que exsurge o direito à reparação integral do dano. Isso porque, em ambos os incisos, observa-se a presença da indenização como elemento de reparação do dano.

O dano, por sua vez, pode ser entendido como o resultado de uma conduta que viola bem juridicamente tutelado (FLUMIGNAN, 2009, p. 42). In casu, os bem violados seriam as diferentes existenciais humanas citadas pelos incisos $\mathrm{V}$ e $\mathrm{X}$ do $\operatorname{artigo} 5^{\circ}$ da Magna Carta de 1988, quais sejam, a moral, a imagem, a material, a intimidade, a vida privada e a honra. Vêse, pois, que o direito à reparação integral do dano está contido na Constituição Federal.

Por sua vez, no art. $5^{\circ}, \mathrm{XXXII,} \mathrm{CF/88,} \mathrm{há} \mathrm{o} \mathrm{compromisso} \mathrm{estatal} \mathrm{em} \mathrm{promover} \mathrm{a}$ defesa do consumidor. Lado outro, ao elencar esse direito como fundamental, o constituinte originário instituiu-o, conforme Sarlet (2013, p. 186) como fim diretivo de ação para os poderes públicos, passando, a ser dever estatal promovê-la através, por exemplo, de políticas públicas. Tanto é assim que a defesa do consumidor aparece novamente no artigo 170, V, $\mathrm{CF} / 88$, dessa vez como diretriz da atividade econômica.

Vale salientar, ainda, que a relevância concedida ao consumidor pela Constituição de 1988 decorre, entre outros, de dois fatores. Primeiro, por ser ele elemento essencial no escoamento da produção de bens de consumo, favorecendo, por consequência, a circulação de capital.

Mais que isso, consoante Grau (2014, p. 249), consumidor é aquele que, em regra, encontra-se em posição de debilidade e subordinação estrutural em relação ao produtor. A precariedade da situação do consumidor, por sua vez, pode ser verificada através da organização que os produtores devem, por lei, possuir, para serem qualificados como empresários.

As exigência legais acima referidas, de seu turno, constam dos artigos 966 e 1.142 do Código Civil (BRASIL, 2002). Nestes, constam as definições de empresário e estabelecimento. Empresário, conforme o artigo 966 do Código Civil de 2002, é aquele que exerce profissionalmente atividade econômica organizada para a produção ou a circulação de bens ou serviços. Já o conceito jurídico de "estabelecimento" é positivado pelo artigo 1.142 
do diploma civilista brasileiro como o complexo de bens organizado, para exercício da empresa, por empresário ou sociedade empresária.

Pelo exposto, viu-se que os incisos V, X e XXXII do artigo $5^{\circ}$ da Constituição Federal de 1988 positivaram a defesa do consumidor, em síntese, através da reparação integral do dano e do compromisso estatal em tutelar os direitos dos mesmos. A relevância constitucional desses direitos é, ainda, realçada quando se analisa referidos enunciados com os conceitos de fundamentalidade material e com o previsto no artigo $5^{\circ}, \S 1^{\circ}$ da Magna Carta de 1988.

A fundamentalidade material, para Sarlet (2017, p. 322), implica uma análise acerca dos direitos em questão conterem decisões fundamentais atinentes à posição do ser humano na sociedade e no Estado. Nos incisos analisados, é patente a relevância dos direitos por eles assegurados no favorecimento do indivíduo no contexto social e estatal. Isso porque, caso não fossem assegurados o direito à indenização e um compromisso estatal protetivo, haveria uma conduta de um particular que excederia os fins econômicos e violado o direito de outrem, o que poderia caracterizar ato ilícito, nos termos dos artigos 186 e 187 do Código Civil (BRASIL, 2002).

Em relação à proteção em relação ao Estado, o mesmo estaria descumprindo um dos fundamentos da República, qual seja, a dignidade da pessoa humana, assegurada no artigo $1^{\circ}$, III, CF/88 (BRASIL, 1988). Isso porque, consoante Sarlet (2015, p. 93), a dignidade tem uma dimensão objetiva, que implica para o Estado compromissos de proteção; e um aspecto subjetivo, relacionado a um conjunto de direitos de caráter prestacional e defensivo. Logo, à míngua de atuação estatal protetiva, o consumidor estaria à mercê de práticas abusivas e teria dificuldade em adquirir os meios necessários à sua subsistência.

Por derradeiro, a relevância constitucional para o país da defesa do consumidor resta evidenciado pelo $\S 1^{\circ}$ do artigo $5^{\circ}$, que dispõe que as normas definidoras de direitos e garantias individuais possuem aplicação imediata, impondo um direito à máxima efetividade e eficácia dos direitos positivados como fundamentais (SARLET, 2017, p. 370).

\section{DO CONCEITO DE EFICIÊNCIA A PARTIR DA ANÁlISE ECONÔMICA DO DIREITO.}


De início, insta consignar que a utilização da doutrina da Análise Econômica do Direito, muito embora incomum na seara jurídica é, no presente artigo, não apenas possível como necessária. Isso porque, a uma, conforme Cooter e Ulen (2016, p. 03), a economia fornece, a partir da aplicação de seus conceitos típicos, uma teoria capaz de prever os efeitos de sanções legais no comportamento humano.

A duas, porquanto os conceitos de eficiência empregados no presente trabalho estão em conformidade com os ditames constitucionais, porquanto, fornece sólida base para a avaliação da qualidade das decisões judiciais, identificando, com antecedência, possíveis prejuízos econômicos.

Assim, serão expostas a seguir as concepções de eficiência elaboradas por Vilfredo Pareto, Robert Cooter, Thomas Ulen, Nicholas Kaldor, John Richard Hicks, Nicholas Mankiw, Ronald Coase e Richard Posner. Dessa forma, fornece-se uma ampla base conceitual que abarca diferentes fases do movimento Direito e Economia. Ao final

A eficiência pode ser definida, segundo Cooter e Ulen (2016, p. 13 e 14), como a situação em que não é possível fornecer a mesma quantidade de produtos com uma combinação mais barata de insumos ou quando não é possível produzir mais usando a mesma combinação de insumos.

Já a eficiência de Pareto ou eficiência alocativa lida com satisfação de preferências individuais e surge quando, em uma situação, é impossível mudá-la para melhorar a situação de um indivíduo sem piorar a situação de nenhum outro. Saliente-se, ademais, que a melhora ou piora da situação é avaliada a partir de uma perspectiva individual e que, nesse critério, caso um indivíduo seja prejudicado, deve ser indenizado até que a alteração no quadro fático seja indiferente para ele, sob pena de poder vetar a transação (COOTER, ULEN; 2016, p. 42 e 191).

Para Mankiw (2018, p. 05), eficiência consiste na capacidade social de retirar a maior quantidade de benefícios a partir dos recursos naturalmente escassos.

O Teorema de Coase, por sua vez, pode ser assim colocado: quando não há custos de transação, por exemplo, acompanhamento de tratativas, o uso eficiente de recursos resultará da negociação particular, independente das disposições legais, pois não se deve ater à causalidade do dano, mas sim à eficiência alocativa de recursos. 
Entretanto, quando os custos de transação são altos a ponto de evitar a negociação, o uso eficiente dos recursos dependerá da distribuição dos direitos de propriedade, os quais, para Coase (1960, p. 19), no sistema de common law do referido autor, eram influenciados pela atuação das Cortes, verdadeiras otimizadoras da alocação de recursos, diante dos conflitos que lhes são apresentados, ainda que de forma empírica e pouco teórica.

No civil law brasileiro, porém, o uso eficiente dos recursos dependerá, primordialmente, da determinação legal, conforme se extrai do princípio da legalidade insculpido no art. 5º II, CF/88 da Constituição Federal de 1988 (BRASIL, 1988).

Na eficiência de Kaldor-Hicks, é possível que haja indivíduos prejudicados desde que os mesmos sejam compensados. Essa reparação, entretanto, da perspectiva de Cooter e Ulen (2016, p. 42-43), não é obrigatória, embora deva ser possível. Acrescentam, ainda, que o benefício auferido deve ser maior do que o prejuízo ocasionado a quem recebe a indenização.

Por sua vez, segundo Posner (1986, p. 11-12), eficiência é a alocação de recursos de forma tal que haja maximização de valor, ou seja, do preço que alguém está disposto a pagar por aquele objeto ou serviço.

Expostos os conceitos de eficiência, passa-se à análise da compatibilidade constitucional dos mesmos para a construção do conceito de eficiência a ser aplicado na análise da Tese número 210 do Supremo Tribunal Federal.

De início, tem-se que o entendimento de Pareto não será adotado, haja vista tomar como referência a satisfação das preferências individuais e permitir ao indivíduo prejudicado vetar a transação, o que contraria a relevância social da defesa do consumidor, conforme se aduz de sua fundamentalidade material anteriormente demonstrada.

Ademais, o conceito de Pareto é impossível de concretização, pois em qualquer relação econômica pode haver perda material, a qual, porém, ocorre em função de um ganho em satisfação. O "ganha-ganha" é, destarte, extremamente utópico.

O conceito de Mankiw, igualmente, embora se reconheça seu acerto e as claras repercussões no cotidiano social, é estritamente construído pela economia, pelo que também não será adotado neste trabalho.

Já o conceito de Cooter e Ulen apresenta elementos relevantes, a exemplo do caráter da indenização como restaurador do status anterior ao dano, pelo que servirá de base, com a 
devida complementação legal, para elaboração, feita adiante, do conceito de eficiência adotado neste trabalho.

In casu, por meio da contribuição de Cooter e Ulen, vê-se que a limitação a priori do teto da indenização restringe a capacidade da mesma em restaurar a vítima ao estágio material anterior ao dano, haja vista pressupor um valor máximo para o prejuízo, sem permitir o exame das particularidades do caso.

Por outra, ainda que se argumente que o seguro adicional previsto na Convenção de Varsóvia-Montreal para cobrir danos que ultrapassem o limite de 1000 Direitos Especiais de Saque previsto no artigo 22, ponto 2 seria um fator de fomento ao caráter da indenização como restaurador do dano, melhor sorte não assistiria aos defensores desse ponto de vista. Isso porque, ao facultar a indenização adicional ao pagamento de um seguro, cria-se um custo adicional para que o indivíduo possa desfrutar do mesmo. Não é, pois, a interpretação mais eficiente quando, em contrapartida, o art. 5, V e X da Constituição Federal de 1988 permitem a indenização integral sem custo adicional. Vê-se, portanto, que as disposições constitucionais de proteção ao consumidor são uma alternativa menos custosa do que as previstas no Pacto de Varsóvia Montreal.

A proposição de Coase, por sua vez, é acertada no que se refere à influência das leis, no Sistema Brasileiro, para distribuição eficiente de riquezas, haja vista, faticamente, não haver situações com custo zero de transação. Ressalte-se, ainda, que a primeira parte de sua proposição tem méritos ao destacar a importância da negociação particular para uma alocação eficiente de recursos, sendo, reitere-se, apenas o seu pressuposto de aplicação equivocado, pois mesmo em transações com custo de tratativa não nulo, ainda é possível a alocação de recursos mais eficiente decorrente da negociação particular.

Note-se, ainda, que o conceito de Kaldor-Hicks muito se aproxima não só da realidade brasileira mas também mundial, por admitir a existência de indivíduos prejudicados nas relações econômicas, desde que indenizados, o que se coaduna com o art. $5^{\circ}, \mathrm{V}$ e $\mathrm{X}$ da Magna Carta de 1988, que assegura a reparação integral do dano como direito fundamental.

Por outra, no conceito de Kaldor-Hicks, o benefício auferido deve ser maior do que o prejuízo ocasionado a quem recebe a indenização. Essa premissa também condiz com o sistema jurídico brasileiro e com a lógica de mercado, porquanto, caso o prejuízo fosse maior que o benefício, a indenização a que o causador do dano estaria obrigado superaria o seu ganho, sendo essa postura, pois, ineficiente. 


\section{A TESE 210 DA SUPREMA CORTE BRASILEIRA E A POSSÍVEL VIOLAÇÃO ÀS GARANTIAS \\ CONSUMERISTAS: UMA ANÁLISE JURÍDICO ECONÔMICA DA PREVALÊNCIA \\ DA CONVENÇÃO DE VARSÓVIA-MONTREAL}

Outrossim, e conforme anteriormente exposto, um prejuízo infligido superior ao lucro auferido poderia caracterizar, inclusive, ato ilícito, nos termos dos arts. 186 e 187 do Código Civil, por violar direito de outrem e exceder os limites impostos pelo fim econômico.

Por fim, o conceito de Posner também possui acertos, haja vista proporcionar, através da eficiente alocação de recursos, a maximização do preço do serviço, acarretando, invariavelmente, maior entrada de recursos financeiros.

A partir dessas contribuições, tem-se o conceito de eficiência adotado neste trabalho: a melhor distribuição de riquezas ocorre quando há o dever legal de indenizar integralmente a parte pelo dano sofrido, sem limites a priori, com vistas à restauração à situação patrimonial original e à garantia do caráter pedagógico da condenação, buscando evitar futuras violações. Referido caráter pedagógico, por sua vez, decorre do fato das empresas internalizarem as reparações como custos. Se as mesmas forem baixas, será vantajoso continuar descumprindo a lei ao invés de investir em adequação.

Igualmente, a indenização deve objetivar a alocação mais eficiente de recursos, favorecendo a circulação de capital através da continuidade do consumo. O quantum indenizatório, por sua vez, deve ser definido apenas subsidiariamente pelo Juízo, em caso de manifesta desproporcionalidade entre dano e indenização.

Por sua vez, a maior aptidão das partes e não do Juízo em encontrar a solução mais eficiente para a lide na qual estão envolvidas decorre do fato da determinação da lei não ser justa por si só, mas na medida em que se coaduna ao caso em concreto (BORBA; 2014, p. 509), bem assim ao fato de que, para Godoy (apud: BORBA, 2014, p. 507-508), o formalismo e os preconceitos legais serem um entrave à prestação jurisdicional eficiente. Logo, deve-se estimular a negociação entre as partes, onde há maior liberdade para encontrar uma solução adequada ao caso em concreto.

Não há que se diga, ainda, que a indenização deve ser limitada com vistas à continuidade da empresa. Isso porque, conforme art. $5^{\circ}, \mathrm{XXIII}, \mathrm{CF} / 88$, a propriedade, sendo a empresa uma forma dela, está condicionada a sua função social, que, por sua vez, abarca o atendimento da legislação pertinente, in casu, as disposições constitucionais relativas à proteção do consumidor.

Haja vista ter sido utilizado como fundamento da tese ora em exame, insta analisar, ainda que brevemente, o enunciado do art. 178, caput, CF/88. Este, por sua vez, determina 
que a lei disporá sobre a ordenação do transporte aéreo, devendo observar, quanto ao transporte internacional, os acordos firmados pela União, atendido o princípio da reciprocidade.

Um dos acordos assinados pelo Brasil é a Convenção de Varsóvia-Montreal, promulgada pelo Decreto $n^{\circ} 5.910 / 06$, a qual, no art. 22, ponto 2, limita a indenização por passageiro para casos de destruição, perda, avaria ou atraso no transporte de bagagem a 1000 Direitos Especiais de Saque, o que equivale, conforme cotação do dia 13/11/2019, a R\$ $5.732,50$.

Faculta-se, porém, mediante pagamento adicional, efetuar declaração especial de valor, caso em que estará o transportador obrigado a pagar uma quantia não superior ao valor declarado, a menos que se comprove que a importância declarada é superior ao valor real da bagagem.

Confrontando-se os arts. 5', V, X, XXXII, 170, V e 178, caput, CF/88 (BRASIL, 1988), observa-se a existência de uma antinomia, definida como:

Oposição que ocorre entre duas normas contraditórias (total ou parcialmente), emanadas de autoridades competentes num mesmo âmbito normativo, que colocam o sujeito numa posição insustentável pela ausência ou inconsistência de critérios aptos a permitir-lhe uma saída nos quadros de um ordenamento dado. (FERRAZ JÚNIOR, 2012, p.179)

A antinomia reside no fato dos arts. $5^{\circ}$, XXXII e 170, V da Constituição Federal de 1988 estabelecerem a proteção do consumidor como direito fundamental e diretriz econômica, enquanto que o art. 178, caput da Magna Carta de 1988 vulnera a mesma ao determinar a observância dos tratados internacionais, entre os quais o de Varsóvia-Montreal, que restringe a reparação do dano, violando direito fundamental (art. $5^{\circ}, \mathrm{V}$ e X, CF/88), a qual seria capaz de tornar a vítima de uma lesão igualmente bem com o dinheiro e a lesão, como ela teria ficado sem o dinheiro ou a lesão (COOTER, ULEN; 2016, p. 191 e 192).

Em outras palavras, como a reparação é capaz de restituir o estado anterior da vítima, sua limitação, tal qual a imposta pela Convenção de Varsóvia-Montreal, restringe a defesa do consumidor ao impedir o retorno ao seu status original, deixando-o em situação insustentável, face ao conflito de critérios para resolução da antinomia, in casu, prevalência dos tratados internacionais ou de uma postura favorável ao consumidor (FERRAZ JÚNIOR, 2012, p. 180). 
Veja-se que essa antinomia é solucionável pela via da ponderação. Antes, porém, cumpre explicitar a diferença entre dispositivo, enunciado normativo e norma, bem assim em que consiste a técnica da ponderação.

Consoante Barroso (2015, p. 228 e 229), dispositivo é parte de um documento normativo, enquanto que enunciado normativo seria o discurso prescritivo extraído de um ou mais dispositivos. Já a norma é o resultado da incidência do enunciado normativo sobre os fatos da causa.

In casu, os dispositivos seriam os arts. $5^{\circ}, \mathrm{V}, \mathrm{X}, \mathrm{XXXII}, 170, \mathrm{~V}$ e 178, caput, CF/88; e os enunciados normativos, as proposições jurídicas que determinam, respectivamente, a promoção estatal da defesa do consumidor, a defesa do consumidor como princípio da ordem econômica, o direito à reparação integral do dano e a observância, quanto ao transporte aéreo internacional, dos acordos da União.

A norma seria a proteção do consumidor através da reparação integral do dano, por constituir compromisso do Estado, direito fundamental (artigo $5^{\circ}, \mathrm{V}, \mathrm{X}$ e XXXII, CF/88); diretriz econômica (art. 170, V, CF/88); e a conduta mais eficiente, tomando por base o conceito de eficiência deste trabalho, qual seja, o de que a melhor distribuição de riquezas ocorre quando há o dever de indenizar integralmente a parte pelo dano ocasionado, com vistas à devolução da mesma à situação anterior ao evento danoso (art. 5, V e X, CF/88).

A ponderação é, para Barroso (2015, p. 373), método de resolução de casos em que colidem duas normas constitucionais de mesma hierarquia, conforme o princípio da unidade e que, ainda conforme referido autor, ao revés de eleger uma norma como premissa maior, trabalha multidirecionalmente, em uma lógica espectral, ao invés do sistema lógico binário da subsunção.

Demais disso, a ponderação ocorre com a identificação do conflito, o exame do contexto fático-normativo que abarca o caso e o exame conjunto dos fatos e normas colacionados, aplicando os princípios da razoabilidade e proporcionalidade. Para diminuir a subjetividade decorrente da aplicação desses princípios, o intérprete deve, ao final, reconduzir as decisões a uma norma legal ou constitucional, utilizar-se de um parâmetro generalizável para evitar casuísmos e produzir a concordância prática dos enunciados em disputa, preservando o núcleo essencial dos direitos e fazendo concessões recíprocas (BARROSO; 2015, p. 373-377). 
A técnica da ponderação, assim, é a mais adequada para o caso porquanto há norma favorável à defesa do consumidor na forma de indenização restauradora do dano (arts. $5^{\circ}, \mathrm{V}$, X e XXXII; e 170, V, CF/88) e um dispositivo constitucional que limita a reparação mercê de um tratado internacional (art. 178, caput, $\mathrm{CF} / 88$ ).

Por outra, a antinomia entre os arts. $5^{\circ}, \mathrm{V}, \mathrm{X}, \mathrm{XXXII}$ e 170 , V e o caput do art. 178, todos da Constituição de 1988, pode ser resolvida também com espeque no princípio da unidade e da concordância prática. $\mathrm{O}$ primeiro pode ser entendido como a diretiva que leva o intérprete da constituição a evitar contradições e superar antinomias internas à Constituição, alcançando unidade político-jurídica (SARLET; 2017, p. 217-219).

Veja-se que a unidade jurídica fomenta a segurança jurídica e a estabilidade do ordenamento legal, enquanto que a unidade política leva, entre outros à garantia de não adoção de posturas estatais conflitantes com a lei ou com compromissos internacionais, entre os quais a Resolução no 39/248, da ONU.

Por outra, vê-se que, topologicamente, o artigo 178 da Constituição está dentro do capítulo da regulação da ordem econômica e financeira. Logo, sua interpretação está condicionada à observância dos princípios que regem a ordem econômica, por tudo, a defesa do consumidor (art. 170, VI, CF/88), a qual, por sua vez, ocorre com o predomínio das hermenêuticas constitucionais favoráveis ao consumidor, na medida em que a reparação integral do dano, conforme art. $5^{\circ} \mathrm{V}$ e X, CF/88, e, conforme já tratado, o retorno da vítima do dano à situação anterior a esse.

Já o princípio da concordância prática pode ser entendido como a diretriz hermenêutica que visa solucionar um conflito normativo com vistas a que os bens jurídicos constitucionalmente protegidos e em contradição preservem sua essência, primando-se, com base no princípio da unidade constitucional, pela otimização dos comandos normativos (HESSE; 1992, p. 45).

Pelo exposto, tem-se que a antinomia entre os arts. $5^{\circ}$, V, X e XXXII; 170, V e 178, caput, $\mathrm{CF} / 88$, pode ser resolvida por meio dos princípios da unidade, concordância prática e da técnica da ponderação. Sua resolução aponta para a prevalência do CDC em relação ao Protocolo de Varsóvia-Montreal. Isso porque esse limita o montante da indenização auferível pelo consumidor que sofreu um dano e que seria capaz de permitir o retorno do mesmo à situação material original, violando os arts $5^{\circ}, \mathrm{V}, \mathrm{X}$. XXXII e 170, V, CF/88 no que diz do direito à reparação integral do dano e o conceito de eficiência elaborado. 


\title{
4 DA INSUSTENTABILIDADE JURÍDICA DA TESE NÚMERO 210 DO SUPREMO TRIBUNAL FEDERAL.
}

Conforme visto anteriormente, o Supremo Tribunal Federal fixou, em regime de repercussão geral, a seguinte tese:

\begin{abstract}
Nos termos do art. 178 da Constituição da República, as normas e os tratados internacionais limitadores da responsabilidade das transportadoras aéreas de passageiros, especialmente as Convenções de Varsóvia e Montreal, têm prevalência em relação ao Código de Defesa do Consumidor.
\end{abstract}

Entretanto, referida tese contraria direitos fundamentais. $\mathrm{O}$ primeiro deles é o direito à reparação integral do dano, o que resta evidente na medida em a Convenção de VarsóviaMontreal estabelece um limite genérico às indenizações por danos à bagagem.

Igualmente, fere-se o direito à proteção do consumidor na medida em que o expõe à situações de possíveis prejuízos materiais não indenizados. Mais que isso, a violação ao referido direito comprova o descompromisso do país com a defesa do consumidor, haja vista, como dito anteriormente, o inciso XXXII do artigo $5^{\circ}$ da Constituição Federal de 1988 instituir um compromisso estatal para com o cidadão.

Mais que isso, a tese da Suprema corte favorece a perpetuação de comportamentos lesivos, porquanto não há a internalização de significativas indenizações. Isso, por sua vez, pode abalar a reputação econômica do Brasil.

\section{CONCLUSÕES}

O presente artigo empreendeu uma análise jurídico econômica da tese número 210 do Supremo Tribunal Federal. Principiou-se pela demonstração da relevância constitucional da defesa do consumidor e da garantia do direito à reparação integral do dano. Não à toa o constituinte originário os positivou como direitos fundamentais.

Com vistas a melhor embasar o artigo, procedeu-se ao estudo de diversos conceitos de eficiência elaborados por teóricos da Escola de Direito e Economia. Isso, por sua vez, possibilitou tornar palpáveis as discussões teóricas anteriormente levantadas. Igualmente, foi 
possível elaborar um conceito de eficiência, qual seja: a melhor distribuição de riquezas ocorre quando há o dever legal de indenizar integralmente a parte pelo dano sofrido, sem limites a priori, com vistas à restauração à situação patrimonial original e à garantia do caráter pedagógico da condenação, buscando evitar futuras violações.

Semelhantemente, a indenização deve objetivar a alocação mais eficiente de recursos, favorecendo a circulação de capital através da continuidade do consumo. O quantum indenizatório, por sua vez, deve ser definido apenas subsidiariamente pelo Juízo, em caso de manifesta desproporcionalidade entre dano e indenização.

Por tudo que foi exposto, é possível concluir que os acórdãos exarados pelo Supremo Tribunal Federal no Recurso Extraordinário nº 636.331 do Rio de Janeiro e no Agravo em Recurso Extraordinário n 766.618 de São Paulo, dos quais se formou a tese número 210 ora analisada, carecem de sustentabilidade jurídico-econômica. A um, porque fragilizam direitos fundamentais, quais sejam, o direito à proteção ao consumidor e à reparação integral do dano, ao restringir o caráter da indenização como fator de devolução do indivíduo que sofreu o dano ao status anterior ao mesmo.

A dois porque o artigo $5^{\circ}, \mathrm{XXXII}, \mathrm{CF} / 88$ constitui, para além de direito fundamental, um compromisso do Estado Brasileiro com sua população, pelo que a adoção pela Suprema Corte de um posicionamento que o fragiliza coloca em dúvida o comprometimento nacional em fomentar o bem estar de sua população.

Igualmente, o entendimento da Suprema Corte Brasileira viola a diretriz da atividade econômica de proteção dos consumidores, os quais devem ser resguardados face ao desequilíbrio observado entre esses e os empresários, que concentram os meios de produção, estão habituados a dinâmica do mercado e, por definição legal, organizam sua atividade produtiva através de um estabelecimento, detendo, por conseguinte, significativa parcela do maior trunfo para o empreendedorismo, mas também para qualquer atividade humana: a informação.

Por outra, os posicionamentos exarados nos acórdãos do Recurso Extraordinário $\mathrm{n}^{\mathrm{o}}$ 636.331/RJ e no Agravo em Recurso Extraordinário n ${ }^{\circ}$ 766.618/SP repercutem, ainda, na reputação internacional do Brasil. Isso porque, para além do direito fundamental, o dispositivo insculpido no art. 5 XXXII da Constituição Federal de 1988 reflete um comprometimento assumido pelo Estado Brasileiro através da Resolução no 39/248, da Organização das Nações 
Unidas, de sorte que o entendimento fixado pela Suprema Corte nacional fragiliza a imagem internacional do país.

Para mais, a decisão do Supremo Tribunal Federal é ineficiente do ponto de vista econômico, porquanto restringe o teto da indenização cabível, o que, além de potencialmente não permitir o retorno do consumidor ao status anterior ao dano, poderá estimular comportamentos das empresas em desconformidade com a norma. Isso porque as reparações de baixa monta pouco representarão nos custos da empresa, pelo que será mais vantajoso do ponto de vista econômico ter de pagar a reparação do que investir na adequação do serviço aos padrões exigidos.

Ainda, pode-se aduzir que, à míngua de sólida fundamentação jurídica e análise econômica da realidade nacional, para além de ausência de acuidade teleológica dos institutos e dispositivos jurídicos objeto deste trabalho, os acórdãos do Supremo Tribunal Federal no Recurso Extraordinário no 636.331/RJ e no Agravo em Recurso Extraordinário no 766.618/SP foram exarados com uma motivação predominantemente política. Dessa forma, é de se duvidar do compromisso da Suprema Corte Brasileira em cumprir com o objetivo da política nacional de relações de consumo de se harmonizar com as relações comerciais, garantindo os direitos do consumidor e fomentando o desenvolvimento econômico, assegurando, também, um dos objetivos da política consumerista brasileira, in casu, a proteção dos interesses econômicos do consumidor em ter um produto de qualidade a preço acessível.

Semelhantemente, a tese $\mathrm{n}^{\mathrm{o}} 210$ do Supremo Tribunal Federal, por formarem precedente, tende a ser observados pelos demais magistrados do país, de sorte que ocorrerá a disseminação de uma cultura jurídica contrária aos preceitos de defesa do consumidor insculpidos na Constituição Federal de 1988.

Dessa forma, conclui-se que a tese firmada pela Suprema Corte brasileira no julgamento do Recurso Extraordinário no 636.331, do Rio de Janeiro e no Agravo em Recurso Extraordinário $\mathrm{n}^{\circ}$ 766.618, de São Paulo possuem evidente caráter político, devendo, pois ser superada.

\section{REFERÊNCIAS}


BARROSO, Luís Roberto. Curso de direito constitucional contemporâneo: os conceitos fundamentais e a construção do novo modelo. São Paulo: Saraiva, 2015.

BENJAMIN, Antônio Herman de Vasconcellos e et al. Código brasileiro de defesa do consumidor: comentado pelos autores do anteprojeto. Rio de Janeiro: Forense, 2017.

BRASIL. Constituição da República Federativa do Brasil de 1988, de 05 de outubro de 1988. Disponível em:

http://www.planalto.gov.br/ccivil_03/constituicao/constituicaocompilado.htm>. Acesso em: 26 abr. 2020.

- Lei $\mathbf{n}^{\mathbf{0}}$ 8.078, de 11 de setembro de 1990. Disponível em: < http://www.planalto.gov.br/ccivil_03/leis/18078.htm>. Acesso em: 03 abr. 2020.

Lei $\mathbf{n}^{\mathbf{0}}$ 10.406, de 10 de janeiro de 2002. Disponível em: <http://www.planalto.gov.br/ccivil_03/LEIS/2002/L10406.htm>. Acesso em: 27 abr. 2020.

COASE, Ronald Harry. The problem of social cost. The Journal of Law and Economics, Chicago, n. 3, p. 1-44, out. 1960. Disponível a partir de: <https://www.journals.uchicago.edu/toc/jle/1960/3/+> Acesso em: 28 jan. 2020.

COOTER, Robert; ULEN, Thomas. Law and Economics. Pearson: London, 2016.

FERRAZ JÚNIOR, Tercio Sampaio. Introdução ao estudo do direito. São Paulo: Atlas, 2012.

FLUMIGNAN, Silvano José Gomes. Dano-evento e dano-prejuízo. 2009. 231 f. Dissertação (Mestrado) - Faculdade de Direito, Universidade de São Paulo, São Paulo, 2009.

GODOY, Arnaldo Sampaio de Moraes. Direito e economia: introdução ao movimento law and economics. Revista Jurídica, Brasília, n. 73, p. 01-10, jun./jul. 2005. Disponível em: < https://revistajuridica.presidencia.gov.br/index.php/saj/article/view/437/431>. Acesso em: 09 abr. 2020.

GRAU, Eros Roberto. A ordem econômica na constituição de 1988. São Paulo: Malheiros, 2014.

HESSE, Konrad. Escritos de derecho constitucional. Madri: Centro de estudios constitucionales, 1992. Traduzido por Pedro Cruz Villalon. Disponível a partir de: <https://www.google.com/search?ei=G162XY_qK5K25OUP1dewgAg\&q=la+interpretacion+ constitucional+konrad+hesse\&oq=la+interpretacion+constitucional+konrad+hesse\&gs_l=psy -ab.3...20368.28608..29051...1.0..0.263.7168.0j10j24.....0....1..gws- 
wiz.imeAD7EMxPo\&ved=0ahUKEwjP4-

mr_731AhUSG7kGHdUrDIAQ4dUDCAs\&uact=5>. Acesso em: 28 abr. 2020.

HICKS, John Richard. The foundations of welfare economics. The economic Journal, Oxford, vol. 49, nº 196, p. 696-712, dez. 1939.

KALDOR, Nicholas. Welfare propositions of economics and interpersonal comparisons of utility. The economic Journal, Oxford, vol. 49, nº 195, p. 549-552, set. 1939.

MANKIW, Nicholas Gregory. Principles of economics. Boston: Cengage Learning, 2018.

MARINONI, Luiz Guilherme; MITIDIERO, Daniel; SARLET, Ingo Wolfgang. Curso de direito constitucional. São Paulo: Saraiva, 2017.

ORGANIZAÇÃO DAS NAÇÕES UNIDAS. Resolução 39/248, de 16 abril de 1985. Disponível a partir

de:

http://www.egov.ufsc.br/portal/conteudo/resolu\%C3\%A7\%C3\%A3o-da-

organiza\%C3\%A7\%C3\%A3o-das-na\%C3\%A7\%C3\%B5es-unidas-onu-n\%C2\%BA-39248-

de-16-de-abril-de-1985-em-ing1\%C3\%AAs>. Acesso em: 01 abr. 2020.

POSNER, Richard Allen. Economic analysis of law. Alphen aan den Rijn: Wolters Kluwer, 1986.

SARLET, Ingo Wolfgang. Dignidade (da pessoa) humana e direitos fundamentais na constituição federal de 1988. Porto Alegre: Livraria do Advogado Editora, 2015.

- Notas introdutórias ao sistema constitucional de direitos e deveres

fundamentais. In: CANOTILHO, José Joaquim Gomes; MENDES, Gilmar Ferreira;

STRECK, Lenio Luiz (Org.). Comentários à constituição do Brasil. São Paulo: Saraiva/Almedina, 2013, p. 183-212.

Supremo Tribunal Federal, Pleno, Agravo em Recurso extraordinário $n^{\circ} 766.618$, de São Paulo, relator Ministro Luís Roberto Barroso, decisão por maioria, Brasília, 25 de maio de 2017.

Disponível

em:

http://portal.stf.jus.br/processos/downloadPeca.asp?id=313246262\&ext=.pdf $>$. Acesso em: 15 fev. 2018.

Idem. Ibidem, Recurso Extraordinário n 636.331, do Rio de Janeiro, relator Ministro Gilmar Ferreira Mendes, decisão por maioria. Brasília, DF, 25 de maio de 2017. Disponível em: < http://portal.stf.jus.br/processos/downloadPeca.asp?id=313246068\&ext=.pdf>. Acesso em: 15 fev. 2018. 